\title{
A Chemosystematic Study of the Moraceae Family: An Analysis of the Metabolites from the Biosynthetic Mixed Pathway (Acetate/Shikimate)
}

\author{
Adriana Lima de Sousa1 ${ }^{1}$, Cibele Maria Stivanin de Almeida1, \\ Maria Auxiliadora Coelho Kaplan², Rodrigo Rodrigues de Oliveira ${ }^{1}$
}

${ }^{1}$ Universidade Estadual do Norte Fluminense Darcy Ribeiro-UENF, Laboratório de Ciências Químicas, CEP 28035200, Campos dos Goytacazes, RJ, Brazil

${ }^{2}$ Núcleo de Pesquisas de Produtos Naturais, Centro de Ciências da Saúde, Bl. H, Universidade Federal do Rio de Janeiro, Cidade Universitária, 21941-590, Rio de Janeiro, RJ, Brasil

Keywords: Moraceae; Chemotaxonomy; Micromolecules.

\begin{abstract}
The Moraceae family is a family of great importance amongst angiosperms. It consists of 37 genera and 1500 species, which are extensively distributed, and 23 genera and approximately 350 species alone have been described in Brazilian biomes. Intra-familiar classification, which is based on morphological and anatomical characteristics and on phylogenetic data, organizes the genera from the Moraceae family within the Artocarpeae, Castilleae, Dorstenieae, Ficeae and Moreae tribes. The purpose of the present study is to collaborate towards the understanding of the relationships between the genera and the tribes of this taxon by exploring chemosystematic data available for the Moraceae family, using grouping and factor analyses (CA and FA, respectively) as chemometric methods. The chemosystematic analysis was performed through a bibliographic survey of the number of occurrence of secondary metabolites isolated from the Moraceae family. Six hundred and seventy-eight papers were identified with the aid of ScIFinder, ranging from 1907 to 2014, enumerating 3728 special metabolites from this family, widely distributed within the Artocarpeae (1242), Castilleae (350), Dorstenieae (486), Ficeae (557) and Moreae (1071) tribes. According to the literature, the metabolite biogenesis in this family derives, mainly, from mixed pathways (1827), followed by the acetate (1280) and shikimate pathways (404). However, each tribe of the family shows a specific trend. For example, while the Artocarpeae and Moreae tribes prefer substances from the mixed route, the most predominant ones in the Castileae and Ficeae tribes are from the acetate pathway. The Dorstenieae tribe, on the other hand, presents a reasonable productive equity in this regard. Furthermore, the factor analysis made it possible to relate genera subordinated in the same tribe, due to their peculiarities regarding special metabolite biosynthesis and evolutionary advancement parameters of protection, oxidation and specialization. Finally, these data confirmed the advanced status of the Moraceae family in angiosperms.
\end{abstract}

\section{Introduction}

The Moraceae is a subordinate family of the Rosales order (APG, 2009), containing 37 genera and 1500 species that show cosmopolitan characteristics (Carauta, 1980; Zerega et al., 2005). This family is notorious in Brazilian biomes, with 23 genera and 350 species present in the country (Romaniuc-Neto, 2010; Carauta, 1996; Carauta, 1980).

The monophyly of Moraceae is supported by morphological, anatomical and molecular characteristics. However, the intra-family taxonomic classification of this family is marked by controversy regarding the distribution of its genera in tribes (Romaniuc-Neto 1999; Berg 1972; Berg 2001; Berg, 2005; Dätwyler \& Weiblen 2004; Ribeiro 2007; Clement \& Weiblen 2009). The crucial point of this disagreement is associated with the fact that some authors use the classification based exclusively on morphological data, while, for the most part, modern and current systems consider molecular, phylogenetic and paleontological data.

In this context, the chemosystematics of the Moraceae family can contribute to the understanding of intra-family taxonomics, due to the relevance of

This article is published under the terms of the Creative Commons Attribution License 4.0

Author(s) retain the copyright of this article. Publication rights with Alkhaer Publications.

Published at: http://www.ijsciences.com/pub/issue/2016-03/

DOI: 10.18483/ijSci.989; Online ISSN: 2305-3925; Print ISSN: 2410-4477 
special metabolites in phylogenetic studies. Thus, the correlation between chemical characteristics, such as oxidation level, skeletal specialization and protection of phenolic structures, with taxonomic position can indicate relationships among the genera of this family. Extensive chemical knowledge is available regarding some of the tribes from the Moraceae family, although these elements have never been used as tools in chemotaxonomic studies. Thus, the aim of the present study was to use the chemosystematic and chemometrics data of special metabolites from a biosynthetic mixed pathway (acetate/shikimate) identified in species from the Moraceae family in order to demonstrate similarities and correlations between Moraceae genera and tribes.

\section{Methodology}

\subsection{Chemosystematic methodology}

The first step in the present study was to collect information on the micromolecular categories identified for the Moraceae family. The chemical profile data for the taxon were obtained by conducting a search on both the Chemical Abstracts and SciFinder Scholar websites, ranging from 1907 to 2014. The keywords used were names of each tribe and their genera.

The results regarding the tribe data and the identified species and metabolites were organized according to the recent phylogenetic studies developed by taxonomists Dätwyler and Weiblen (2004), specialists on the Moraceae family. Subsequently, the data were organized in tables displaying their Occurrence Frequency (OF), Diversification Index (DI), Number of Types (NT) and evolutionary parameters such as hydroxyl protection mechanisms. Oxidation and specialization evolutionary advancement parameters ( $\mathrm{EA}_{\mathrm{o}}$ and $\mathrm{EA}_{\mathrm{E}}$, respectively) were also determined for the Moraceae family micromolecules (Gottlieb et al 1996).

\subsection{Multivariate Statistical Analysis}

In the present study the factor analysis and cluster analysis approaches were applied. The former provides the tools to analyze the inter-relationships of structure (correlations) of a large number of variables, defining sets of variables which are strongly interrelated, known as factors (representing the dimensions which summarize or explain the original set of observed variables). The main purpose of the second approach is to aggregate objects based on their characteristics, by recognizing and indicating relationship patterns (Hair et al, 1999).

To make it easier to manipulate the data, acronyms instead of genera names were used, as follows: Representatives of the Artocarpeae tribe: A1 Artocarpus; A2 - Batocarpus; A3 - Clarissa; A4 Hulletia; A5 - Parartocarpus; A6 - Prainea; A7 -
Treculia. Representatives of the Castileae tribe: $\mathrm{C} 1-$ Antiaris; C2 - Antiaropsis; C3 - Castila; C4 Helicostylis; C5 - Maquira; C6 - Mesogyne; C7 Naucleopsis; C8 - Perebea; C9 - Poulsenia; C10 Pseudolmedia; C11 - Sparratosyce. Representatives of the Dorstenieae tribe: D1 - Bosqueiopsis; D2 Brosimum; D3 - Dorstenia; D4 - Helianthostylis; D5 - Scyphosyce; D6 - Trilepisium; D7 Trymatococcus; D8 - Utsetela. Representative of the Ficeae tribe: F1 - Ficus. Representatives of the Moreae tribe: M1 - Bagassa; M2 - Bleeckrodea; M3 - Broussonetia; M4 - Fatoua; M5 - Maclura; M6 Milicia; M7 - Morus; M8 - Sorocea; M9 - Streblus; M10 - Trophis.

\section{Results and discussion}

\subsection{Chemosystematic study of micromolecules resulting from the mixed acetate/shikimate pathway of the Moraceae family}

The analysis of 682 publications, ranging from 1907 to 2014 , shows a widespread occurrence of special metabolites from the mixed pathway $(\mathrm{OF}=1827)$ with a high diversity index (DI = 32886). The high diversity of the Moraceae family can be explained by the presence of 18 skeleton types, as displayed in Figure 1, although this diversity is mainly concentred in three tribes, namely Moreae, Artocarpeae and Dorstenieae (Table 1). The preponderance of the flavonoid class is noteworthy, with high structural diversity in all Moraceae tribes. These substances are composed of a regular skeleton with protected hydroxyl groups, although more specialized types also exist, such as isoflavones and Diels Alder adducts.

Diels Alder adducts are formed by the condensation of two flavonoids or stilbenes, or both. These compounds show a high degree of prenyl groups linked to the aromatic carbon, which are usually present in flavonoid skeletons, and have been shown to be a characteristic of the Moraceae family. The main flavonoid skeletons are flavones $(\mathrm{OF}=714)$, chalcones $(\mathrm{OF}=206)$, flavonols $(\mathrm{OF}=171)$, flavonoids $(\mathrm{OF}=133)$ and isoflavones $(\mathrm{OF}=63)$. Flavones and chalcones are generally found in Moraceae tribes, with the exception of Castileae and Ficeae, respectively. The higher prevalence of flavones when compared to flavonols $(\mathrm{fo} / \mathrm{fl}=4.2)$ is an important correlation parameter between morphological and chemical characteristics, and demonstrates that the Moraceae family is more advanced than basal angiosperms. This evolution is confirmed by two parameters, the Sporne Index $(\mathrm{SI}=48)$ and the Herbaceousness Index $(\mathrm{HI}=25)$. The Artocarpeae tribes contribute positively to these indices due to their high flavone production. The other tribes show either low flavone production or equal production of both flavones and flavanols (Table 1) (Harborner, 1977; Soares \& Kaplan, 2001). 


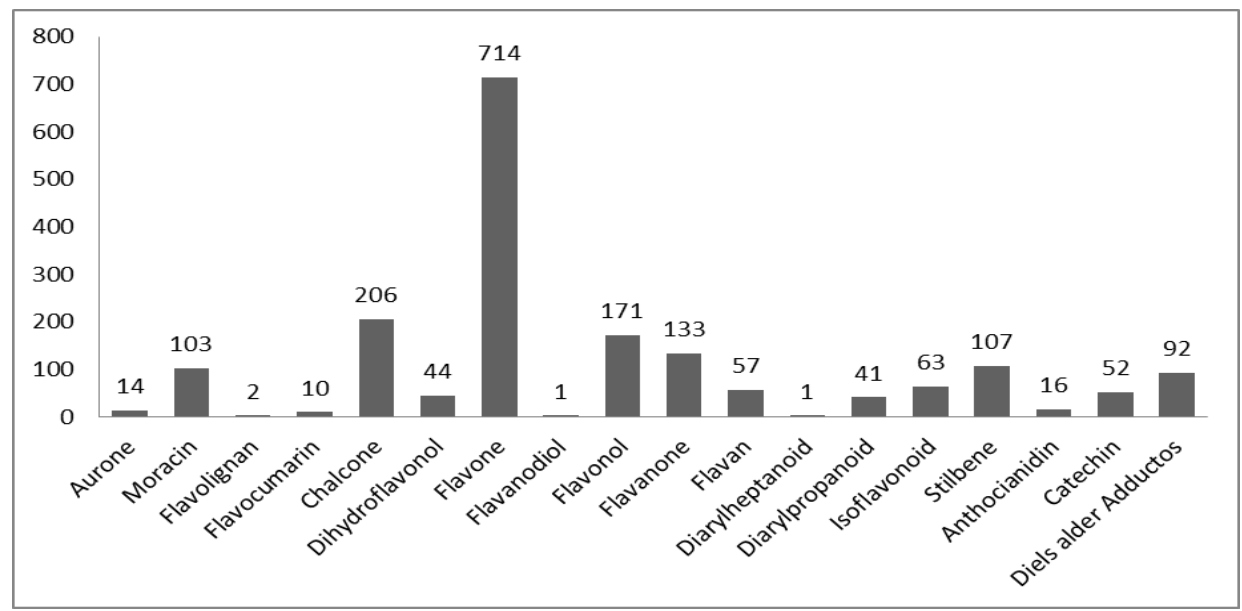

Figure 1. Frequency of metabolic classes originating from the mixed acetate/shikimate pathway in the Moraceae family.

Specialized types of flavonoids, such as isoflavones, aurones and Diels Alder adducts, occur in the Moreae, Artocarpeae and Dorstenieae tribes. The presence of these compounds points to a higher evolution status of these tribes due to presence of more specific enzymes (Gottlieb et al 1996). Stilbenes are also present in this family, found in the Moreae, Artocarpeae, Dorstenieae and Ficeae tribes.

The Artocarpeae tribe shows a higher occurrence of this class when compared to other tribes, although the Moreae tribe shows specialized skeletons, such as moracins and Diels Alder adducts. The Castileae tribe shows a modest variety of occurrence frequency, with only three classes: flavanones $(\mathrm{OF}=17)$, chalcones $(\mathrm{OF}=12)$ and flavonols $(\mathrm{OF}=3)$. A small number of flavonoid classes can be explained by the high production of chalcones and flavanones, which are biosynthetic intermediaries for other flavonoids. The Ficeae tribe has 9 categories of metabolites derived from the mixed biosynthesis: flavones $(\mathrm{OF}=26)$, flavonols $(\mathrm{OF}=24)$, isoflavones $(\mathrm{OF}=17)$, catechins $(\mathrm{OF}=16)$, anthocyanidins $(\mathrm{OF}=5)$, chalcones $(\mathrm{OF}=3)$, flavanones $(\mathrm{OF}=3)$, stilbenes $(\mathrm{OF}=1)$ and flavandiols $(\mathrm{OF}=1)$. Although this is a unique monotypic tribe, its metabolic production is similar to that of the other tribes from the Moraceae family. Diarylheptanoids and diarylpropanoids have a restricted occurrence in the Moraceae family, present only in the Dorstenieae and Moreae tribes, respectively. Figure 2 summarizes the micromolecules occurrence frequency each tribe.

Table 1. Occurrence frequency (OF) of metabolite categories from the mixed acetate/shikimate pathway. Tribes: A: Artocarpeae; C: Castilleae; D: Dorstenieae; F: Ficeae; M: Moreae. Identifying categories: Fl=Flavanone; Fla=Flavana; DiH=Diarylheptanoid; Dip=Diarylpropanoid; I=Isoflavonoid; S=Stilbene; An=Anthocianidin; $\mathrm{Ca}=$ Catechin; $\mathrm{Ada}=$ Diels Alder adducts; $\mathrm{Au}=$ Aurone; Mo=Moracins; Flg=Flavolignan; Flc=Flavocumarin; $\mathrm{Ch}=$ Chalcone; Di= Dihydroflavonol; Fon=Flavone; Fdol= Flavanodiol; Fol=Flavonol.

\begin{tabular}{|c|c|c|c|c|c|c|c|c|c|c|c|c|c|c|c|c|c|c|}
\hline $\begin{array}{l}\text { Tri } \\
\text { bes }\end{array}$ & $\mathbf{l}^{\mathrm{F}}$ & la & ${ }_{\text {ih }}^{D}$ & ip & $\mathbf{I}$ & $\mathbf{S}$ & $\mathbf{n}^{\mathrm{A}}$ & $a^{C}$ & $\mathbf{d a}^{\mathbf{A}}$ & $\mathbf{u}^{\mathbf{A}}$ & $\mathbf{o}^{\mathbf{M}}$ & $\lg F$ & lc & h & ${ }_{\text {i }} \quad$ D & $\begin{array}{c}\text { F } \\
\text { on }\end{array}$ & $\begin{array}{r}\text { F } \\
\text { dol }\end{array}$ & ${ }_{\text {ol }} \mathbf{F}$ \\
\hline A & $8^{5}$ & 0 & 0 & 0 & 3 & 87 & 1 & $1^{3}$ & $\begin{array}{ll} & 1 \\
3 & \\
\end{array}$ & 9 & $1^{5}$ & 0 & 3 & $\begin{array}{l} \\
6 \\
\end{array}$ & 9 & $\begin{array}{r}5 \\
59 \\
\end{array}$ & 0 & $2^{2}$ \\
\hline $\mathrm{C}$ & $7^{1}$ & 0 & 0 & 0 & 0 & 0 & 0 & 0 & 0 & 0 & 0 & 0 & 0 & $2^{1}$ & 0 & 0 & 0 & 3 \\
\hline D & $1^{2}$ & $5^{1}$ & 1 & 0 & 8 & 1 & 0 & 2 & 8 & 0 & 1 & 0 & 2 & $0^{6}$ & 1 & $0^{3}$ & 0 & $3^{1}$ \\
\hline $\mathrm{F}$ & 3 & 0 & 0 & 0 & $7^{1}$ & 1 & 5 & $6^{1}$ & 0 & 0 & 0 & 0 & 0 & 3 & 2 & $6^{2}$ & 1 & $4^{2}$ \\
\hline $\mathbf{M}$ & $4^{3}$ & $2^{4}$ & 0 & $1^{4}$ & $5^{3}$ & 72 & $\begin{array}{ll} & 1 \\
0 & \end{array}$ & 3 & $1^{7}$ & 8 & $1^{5}$ & 2 & 5 & $2^{3}$ & $2^{3}$ & $8^{9}$ & 0 & $09^{1}$ \\
\hline
\end{tabular}




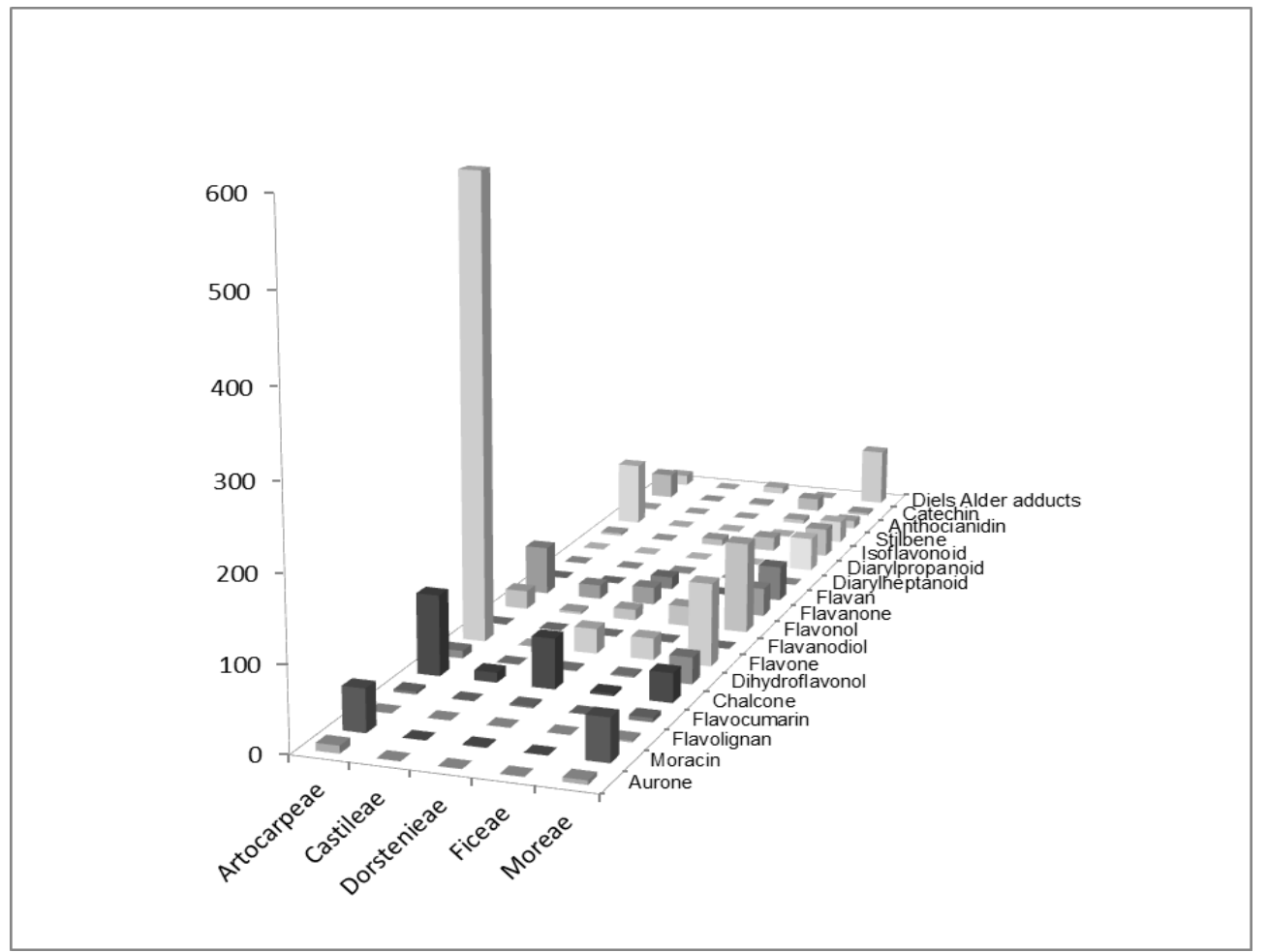

Figure 2. Metabolic classes resulting from the mixed (acetate/shikimate) pathway in the Moraceae family.

\subsubsection{Micromolecule chemical modulator indices from the mixed pathway analysis}

Phenolic compounds originating from the mixed (acetate/shikimate) biosynthesis pathway are characterized by showing low hydroxyl protection by methylation, glycosylation and prenylation, as observed in Figure 3. The indices are summarized in table 2. When comparing the index values of each protection parameter with unprotected values, it was observed (Table 3 and Figure 4) that, when micromolecules from the mixed pathway are protected, this usually occurs by prenylation, with the exceptions of the Clarisia, Antiaris, Trilepisium, Ficus and Streblus genera, that either show this protection at low frequencies or do show protection mechanisms at all. The isoprene units are linked to the aromatic carbon close to the hydroxyl groups, contributing to oxygen protection by cyclization. Cprenylation reactions are very rare in primitive woody Angiospermae, being common only in advanced Angiospermae groups.

The comparison between O-methylation and Oglycosylation protection parameters indicates that Moraceae tribes are characterized by higher protection by $\mathrm{O}$-methylation instead of $\mathrm{O}$ glycosylation (Figure 3). This demonstrates an evolved character of this taxon, due to low energetic consumption and the efficiency of this kind of protection. These results are consistent with the APG III classification and corroborate with detachment of Moraceae family from Eudicotyledoneae clade (Soltis et al, 2010).

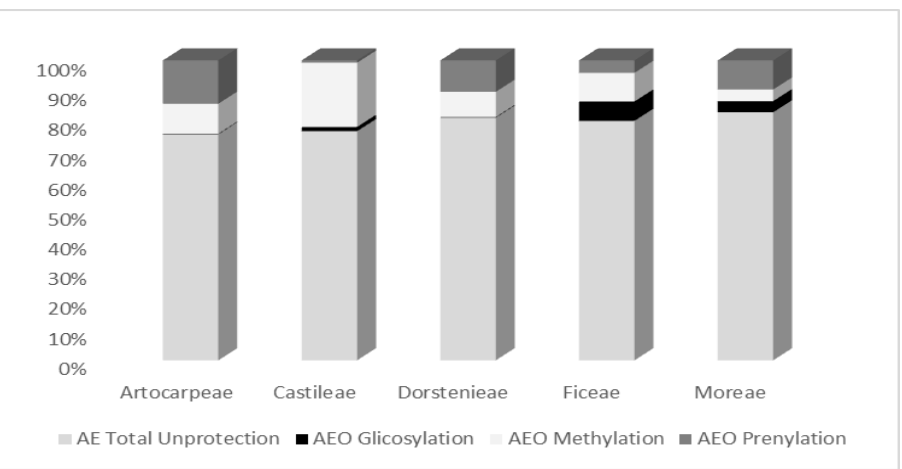

Figure 3. Correlations between the evolutionary protection and unprotection mixed acetate/shikimate pathway advancement parameters of the Moraceae tribes investigated in the present study. 
A Chemosystematic Study of the Moraceae Family: An Analysis of the Metabolites from the Biosynthetic Mixed Pathway (Acetate/Shikimate)

Table 2. Values of the evolutionary protection and unprotection mixed pathway advancement parameters of the

Moraceae tribes investigated in the present study.

\begin{tabular}{llllll}
\hline Tribes & EAO $_{\text {Protection }}$ & EAO $_{\text {Unprotection }}$ & EAO $_{\text {Glycosylation }}$ & EAO $_{\text {Methylation }}$ & EAO $_{\text {Prenylation }}$ \\
\hline Artocarpeae & 1.1573 & 3.5501 & 0.0073 & 0.4725 & 0.6797 \\
Castileae & 0.2359 & 0.7641 & 0.0141 & 0.2141 & 0.0078 \\
Dorstenieae & 0.5686 & 2.4361 & 0.0051 & 0.2536 & 0.3154 \\
Ficeae & 0.1988 & 0.7986 & 0.0645 & 0.0954 & 0.0415 \\
Moreae & 1.3239 & 6.5509 & 0.295 & 0.3064 & 0.7689 \\
\hline
\end{tabular}

Table 3. Values of the evolutionary protection and unprotection mixed pathway advancement parameters of the Moraceae generaO-G: O-glycosylation; O-M:O-metylation,O-P: O-prenylation; O-PT: total O-Protection; O-DT: total O-unprotection; C-P: C-prenylation.

\begin{tabular}{|c|c|c|c|c|c|c|}
\hline Genera & O-G & O-M & O-P & O-PT & O-UT & C-P \\
\hline Artocarpus & 0.0073 & 0.0697 & 0.1440 & 0.2188 & 0.7600 & 0.2894 \\
\hline Batocarpus & 0.0000 & 0.1250 & 0.2500 & 0.3750 & 0.6250 & 0.1667 \\
\hline Clarissa & 0.0000 & 0.2778 & 0.0000 & 0.2778 & 0.7222 & 0.2222 \\
\hline Hulletia & 0.0000 & 0.0000 & 0.0000 & 0.0000 & 0.0000 & 0.0000 \\
\hline Parartocarpus & 0.0000 & 0.0000 & 0.2857 & 0.2857 & 0.6429 & 0.2436 \\
\hline Prainea & 0.0000 & 0.0000 & 0.0000 & 0.0000 & 0.0000 & 0.0000 \\
\hline Treculia & 0.0000 & 0.0000 & 0.0000 & 0.0000 & 10.000 & 0.0286 \\
\hline Antiaris & 0.0141 & 0.2141 & 0.0078 & 0.2359 & 0.7641 & 0.2777 \\
\hline Antiaropsis & 0.0000 & 0.0000 & 0.0000 & 0.0000 & 0.0000 & 0.0000 \\
\hline Castila & 0.0000 & 0.0000 & 0.0000 & 0.0000 & 0.0000 & 0.0000 \\
\hline Helicostylis & 0.0000 & 0.0000 & 0.0000 & 0.0000 & 0.0000 & 0.0000 \\
\hline Maquira & 0.0000 & 0.0000 & 0.0000 & 0.0000 & 0.0000 & 0.0000 \\
\hline Mesogyne & 0.0000 & 0.0000 & 0.0000 & 0.0000 & 0.0000 & 0.0000 \\
\hline Naucleopsis & 0.0000 & 0.0000 & 0.0000 & 0.0000 & 0.0000 & 0.0000 \\
\hline Pereba & 0.0000 & 0.0000 & 0.0000 & 0.0000 & 0.0000 & 0.0000 \\
\hline Poulsenia & 0.0000 & 0.0000 & 0.0000 & 0.0000 & 0.0000 & 0.0000 \\
\hline Pseudolmedia & 0.0000 & 0.0000 & 0.0000 & 0.0000 & 0.0000 & 0.0000 \\
\hline Sparratosyce & 0.0000 & 0.0000 & 0.0000 & 0.0000 & 0.0000 & 0.0000 \\
\hline Bosqueiopsis & 0.0000 & 0.0000 & 0.0000 & 0.0000 & 0.0000 & 0.0000 \\
\hline Brosimum & 0.0051 & 0.1075 & 0.1129 & 0.2255 & 0.7745 & 0.1082 \\
\hline Dorstenia & 0.0000 & 0.0211 & 0.2025 & 0.2181 & 0.7866 & 0.3688 \\
\hline Helianthostylis & 0.0000 & 0.0000 & 0.0000 & 0.0000 & 0.0000 & 0.0000 \\
\hline Scyphosyce & 0.0000 & 0.0000 & 0.0000 & 0.0000 & 0.0000 & 0.0000 \\
\hline Trilepisium & 0.0000 & 0.1250 & 0.0000 & 0.1250 & 0.8750 & 0.0000 \\
\hline Trymatococcus & 0.0000 & 0.0000 & 0.0000 & 0.0000 & 0.0000 & 0.0000 \\
\hline Utsetela & 0.0000 & 0.0000 & 0.0000 & 0.0000 & 0.0000 & 0.0000 \\
\hline Ficus & 0.0645 & 0.0954 & 0.0415 & 0.1988 & 0.7986 & 0.6589 \\
\hline Bagassa & 0.0000 & 0.0500 & 0.0167 & 0.0667 & 0.8333 & 0.0560 \\
\hline Bleeckrodea & 0.0000 & 0.0000 & 0.0000 & 0.0000 & 0.0000 & 0.0000 \\
\hline Broussonetia & 0.0398 & 0.0509 & 0.0524 & 0.1434 & 0.8518 & 0.1771 \\
\hline Fatoua & 0.0000 & 0.0000 & 0.0833 & 0.0833 & 0.9167 & 0.3111 \\
\hline Maclura & 0.0300 & 0.0205 & 0.1372 & 0.1646 & 0.8815 & 0.1781 \\
\hline Milicia & 0.0000 & 0.0000 & 0.2167 & 0.2167 & 0.7833 & 0.1556 \\
\hline Morus & 0.0606 & 0.0282 & 0.0821 & 0.1095 & 0.8089 & 0.1447 \\
\hline Sorocea & 0.0085 & 0.0000 & 0.1805 & 0.2268 & 0.7883 & 0.1486 \\
\hline Streblus & 0.1561 & 0.1568 & 0.0000 & 0.3129 & 0.6871 & 0.0000 \\
\hline Trophis & 0.0000 & 0.0000 & 0.0000 & 0.0000 & 0.0000 & 0.0000 \\
\hline
\end{tabular}




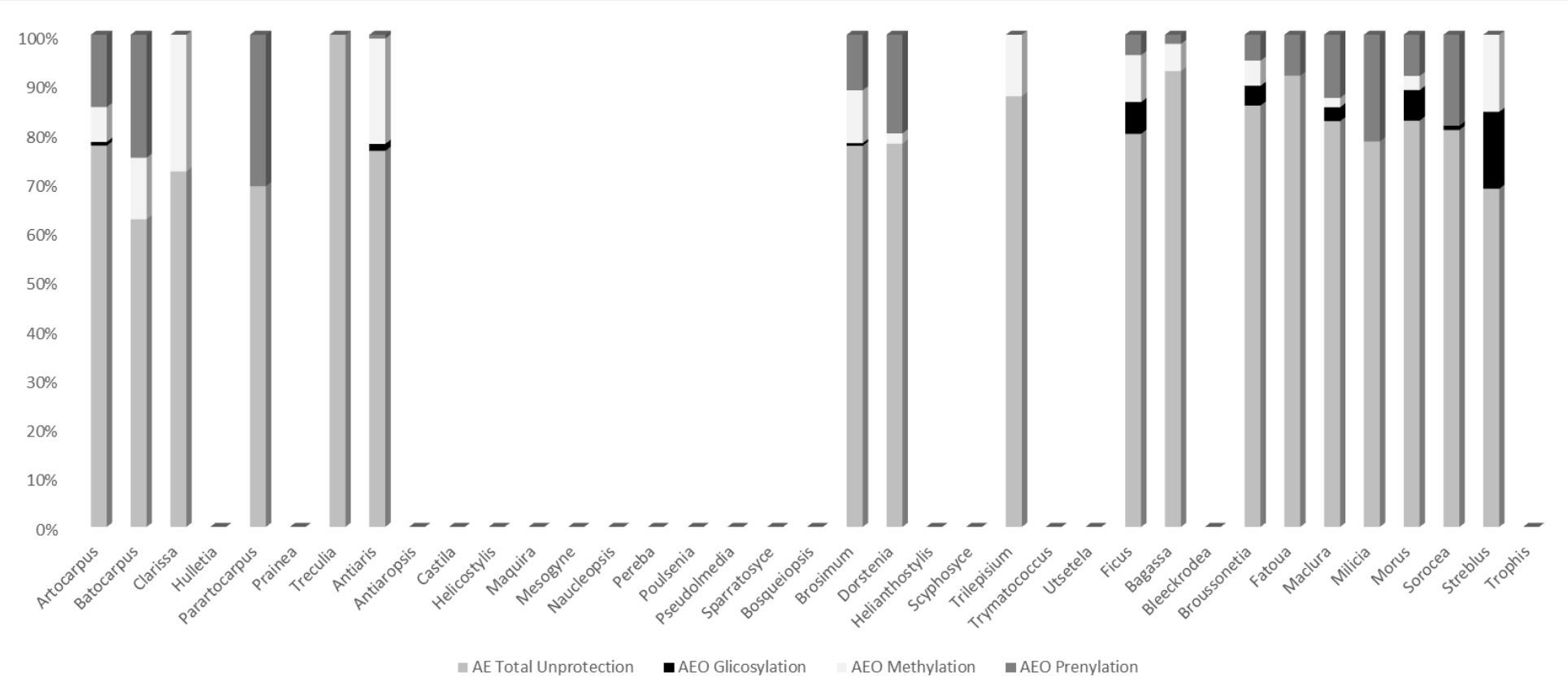

Figure 4. Relationships between evolutionary protection and unprotection mixed (acetate/shikimate) pathway advancement parameters of the Moraceae generas.

\subsection{Analysis of the specialization and oxidation} evolutionary advancement parameters of the Moraceae family

The micromolecules from the mixed pathway in the Moraceae family were analyzed in order to determine the oxidation index (OI) and the skeleton specialization index (SI). All Moraceae genera show a low oxidation index, with the exception of Streblus, which showed a positive value. The skeleton specialization in this genus is high due to the presence of isoprene units that confer an increase in the number of links and cyclization. The correlation between the oxidation $\left(\mathrm{EA}_{\mathrm{O}}\right)$ and specialization $\left(E A_{E}\right)$, evolutionary advancement parameters of each genus (Table 4) indicates a clear separation between these genera, albeit not sufficient to separate them in tribes, as noted in Figure 5. However, it is clear that there is a moderate proximity between Morus, Sorocea, Maclura, Milicia and Broussonetia genera belonging to the Moreae tribe. 
A Chemosystematic Study of the Moraceae Family: An Analysis of the Metabolites from the Biosynthetic Mixed Pathway (Acetate/Shikimate)

Table 4. Oxidation and specialization evolutionary advancement parameter indices of the metabolites from the mixed acetate/shikimate pathway investigated in the present study.

\begin{tabular}{llllll}
\hline Genera & EAo & EAE & Genera & EAo & EAE \\
\hline Artocarpus & -0.2326 & 0.2214 & Brosimum & -0.4675 & 0.3022 \\
Batocarpus & -0.1952 & 0.3655 & Dorstenia & -0.3812 & 0.3136 \\
Clarissa & -0.5111 & 0.3644 & Helianthostylis & 0.0000 & 0.0000 \\
Hulletia & 0.0000 & 0.0000 & Scyphosyce & 0.0000 & 0.0000 \\
Parartocarpus & -0.6484 & 0.4834 & Trilepisium & -0.0735 & 0.0747 \\
Prainea & 0.0000 & 0.0000 & Trymatococcus & 0.0000 & 0.0000 \\
Treculia & -0.135 & 0.0667 & Utsetela & 0.0000 & 0.0000 \\
Antiaris & -0.3118 & 0.242 & Ficus & -0.0774 & 0.2331 \\
Antiaropsis & 0.0000 & 0.0000 & Bagassa & -0.2701 & 0.1132 \\
Castila & 0.0000 & 0.0000 & Bleeckrodea & 0.0000 & 0.0000 \\
Helicostylis & 0.0000 & 0.0000 & Broussonetia & -0.2760 & 0.1870 \\
Maquira & 0.0000 & 0.0000 & Fatoua & -0.6800 & 0.4333 \\
Mesogyne & 0.0000 & 0.0000 & Maclura & -0.1648 & 0.2376 \\
Naucleopsis & 0.0000 & 0.0000 & Milicia & -0.3286 & 0.3543 \\
Pereba & 0.0000 & 0.0000 & Morus & -0.2321 & 0.2577 \\
Poulsenia & 0.0000 & 0.0000 & Sorocea & -0.2408 & 0.2051 \\
Pseudolmedia & 0.0000 & 0.0000 & Streblus & 0.0412 & 0.1726 \\
Sparratosyce & 0.0000 & 0.0000 & Trophis & 0.0000 & 0.0000 \\
Bosqueiopsis & 0.0000 & 0.0000 & & & \\
\hline
\end{tabular}

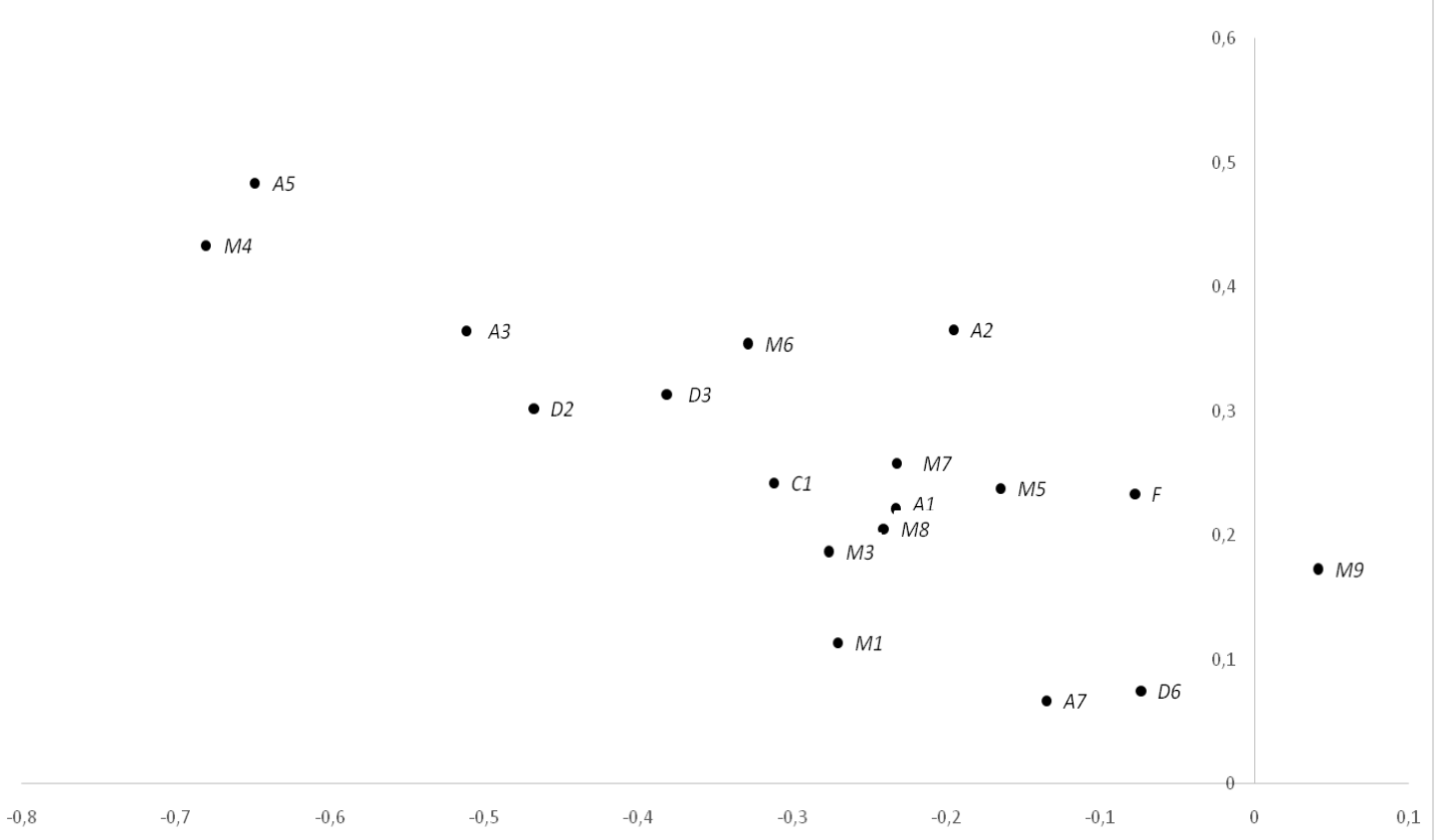

Figure 5. Correlation between the $\mathrm{EA}_{\mathrm{E}}$ and $\mathrm{EA}_{\mathrm{O}}$ parameters. 


\subsection{Exploration of the chemosystematic data of the Moraceae family}

3.2.1. Chemometric analysis of the micromolecules from the mixed pathway

When analyzed separately, the chemosystematic parameters did not compose a clear genera group that could be used as an intra-family taxonomic classification. However, when used in association to the chemometric exploration, by the application of the factor and cluster analyses, some well-defined groups could be observed. The O-prenylation, Oprotection, O-unprotected, C-prenylation and $\mathrm{EA}_{O}$ and $\mathrm{EA}_{\mathrm{E}}$ parameters formed the first factor (Factor 1) (accounting for $49.7 \%$ of the total data variance). The second factor (Factor 2) (accounting for $22.2 \%$ of the total data variance) was formed by the Moraceae tribes and genera, based on the report by Dätwyler and Weiblen (2004), while Factor 3 (accounting for $13.2 \%$ of the total data variance) was formed by the O-glycosylation and O-methylation parameters. Figure 6 displays the bidimensional diagram of the factor analysis of the 37 Moraceae genera investigated in the present study, revealing a smooth dispersion between genera. When analyzing this diagram, it is clear that the genera for which there is no occurrence of micromolecules from the mixed acetate/shikimate route overlap between -0.5 and -1.0. Factor 1 caused a dispersion of the Moraceae genera, although the tribe representatives are near each other. The two groups defined within circles did not present any micromolecule occurrence data, this being the main reason for their formation. Therefore, neither factor impacted the distribution profile.

The Moreae tribe showed scattered genera due to peculiarities attributed by the variables that compose Factor 1. Therefore, it was possible to observe that the Fatoua and Milicia genera present a higher degree of correlation with each other due to their similarities, such as hydroxyl protection exclusively by prenylation.

The Streblus genus did not present correlations with other genera, due to the high oxidation evolutionary advancement parameter value (EAo: 0.0412), as displayed in Figure 5, and the high value of protection of phenolic hydroxyls, as shown in Figure 4 and Table 3. These discrepancies between Streblus and other Moreae genera are not surprising, since the Streblus genus shows an enormous variation in growth, breeding systems, inflorescence and morphology when compared to the tribe in which it is inserted, as well as being paraphyletic (Clement \& Weiblen, 2009; Conn, 2015).
When analyzing Figure 6, it is possible to observe that the Ficus genus (Ficeae) shows considerable affinity with the genera that compose the Moreae tribe, especially those that show considerable phenolic hydroxyl protection by glycosylation, except for Sorocea, Milicia and Fatoua.

The Antiaris genus (Castilleae) is shown close to the Artocarpus genus (Artocarpeae), due to a similarity in oxidation $\left(\mathrm{EA}_{\mathrm{O}}\right)$ and structure specialization $\left(\mathrm{EA}_{\mathrm{E}}\right)$ evolutionary advancement parameters. It should also be noted that both genera display entomophily pollination, mediated by mosquitoes that feed on their staminate inflorescences (Zerega et al, 2010).

The "breadfruit" tribe, Artocarpeae, rich in morphological and anatomical heterogeneities, features a large genera dispersion due to certain chemical peculiarities of the genera species, while the Parartocarpus and Treculia genera are more divergent and do not show any affinities with other Artocarpeae genera.

The Parartocarpus genus is highly rich in protection by prenylation, and, consequently, shows a high specialization $\left(\mathrm{EA}_{\mathrm{E}}\right)$ and low oxidation index $\left(\mathrm{EA}_{\mathrm{O}}\right)$, thus displaying distinct chemical characteristics from other Artocarpeae genera. Consequently, Parartorcarpus chemosystematic data corroborate the claim made by Zerega et al. (2010), which confirms that this taxon has tribal status.

While the Treculia genus is distinguished from the Artocarpeae tribe, since it presents metabolites derived from the mixed acetate/shikimate pathway with unprotected hydroxyls and at the same time, few C-prenylations. In a previous study, Zerega et al. (2010) had already suggested that this taxon be transferred to Dorstenieae. In addition, the present chemosystematic study observed greater affinity between the Treculia and Trilepisium genera, both belonging to the Dorstenieae tribe.

The chemosystematic data of the Dorstenieae tribe ratifies the distance of the Trilepsium genus from the Brosimum and Dorstenia genera, as demonstrated by previous phylogenetic studies (Dätwyler and Weiblen (2004). Both the Dorstenia and Brosimum genera are more specialized and have lower oxidation indices when compared to the Trilepisium genus. This is due to the fact that they have a higher number of protected hydroxyls, either by prenylation or methylation, in addition to high levels of Cprenylation, while the Trilepisium genus is distinguished by having more unprotected hydroxyls, although it applies the methylation protection mechanism exclusively. 


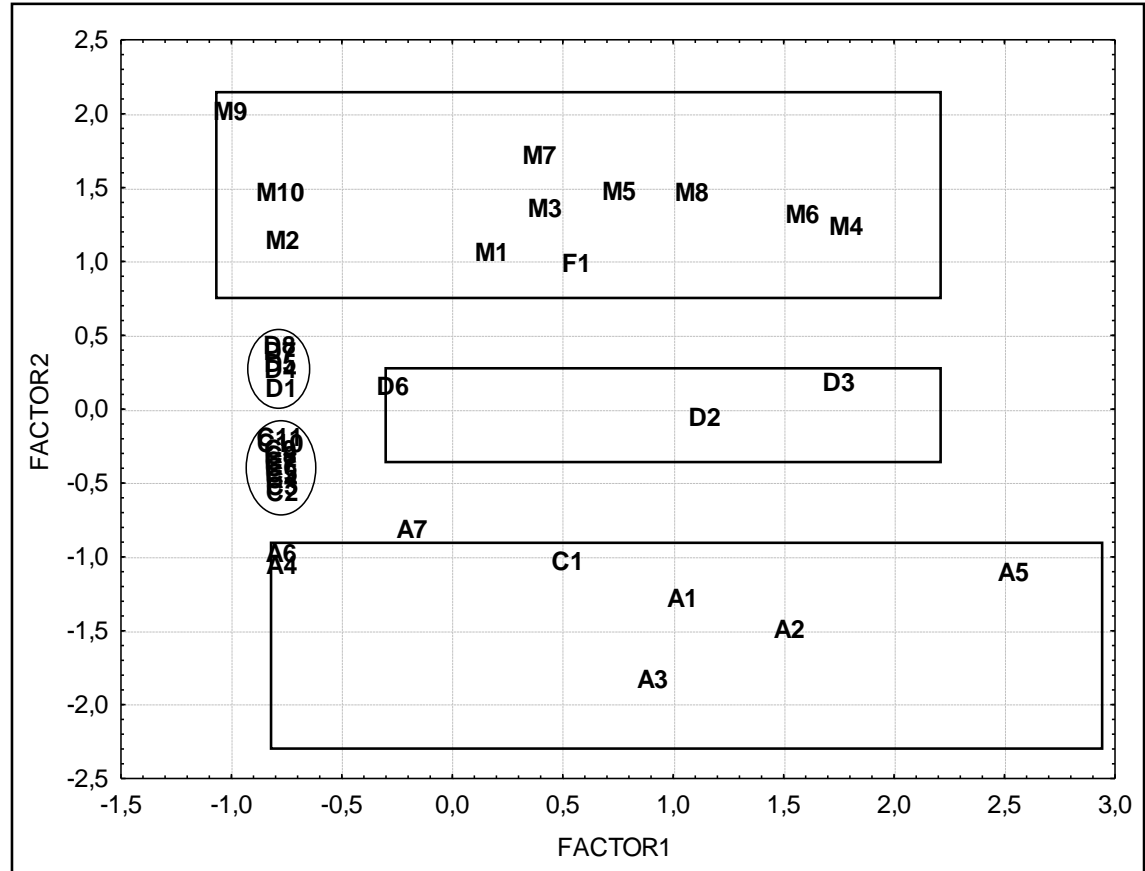

Figure 6. Bidimensional diagram (Factor $1 \times$ Factor 2) indicating the interrelationships between the 37 genera of the Moraceae family analyzed in the present study.

In order to observe the genera distribution from another perspective, a bidimensional diagram confronting Factor 2 and Factor 3 is displayed in Figure 7, in which Factor 3 consists of the glycosylation and prenylation protection parameters. After plotting this graph, it was possible to observe equal distribution of the investigated genera. It is noteworthy that the Streblus genus is well distanced from other Moreae tribe genera, which may be related to the fact that this genus has a high oxidation index $\left(\mathrm{EA}_{\mathrm{O}}\right.$ Streblus $\left.=0.0412\right)$ and high protection index by methylation (O-M Streblus: 0.15668) and glycosylation (O-G Streblus: 0,1561) when compared to the other
Moreae tribe genera. Legitimizing the previous factor analysis comparing Factor 1 and Factor 2, and phylogenetic analyses (Dätwyler and Weiblen, 2004), this taxon is distanced far from its peers. From this perspective, it is also possible to observe differences between the Ficeae and the Moreae tribes. While the Moreae tribe, in general, shows a prevalence of hydroxyl protection by prenylation, the Ficeae tribe shows a predominance of protection by methylation and glycosylation. Thus, what brings together the Ficeae and Moreae tribes is their ability to protect their hydroxyls by glycosylation, as can be observed in Figure 4 and Table 3.

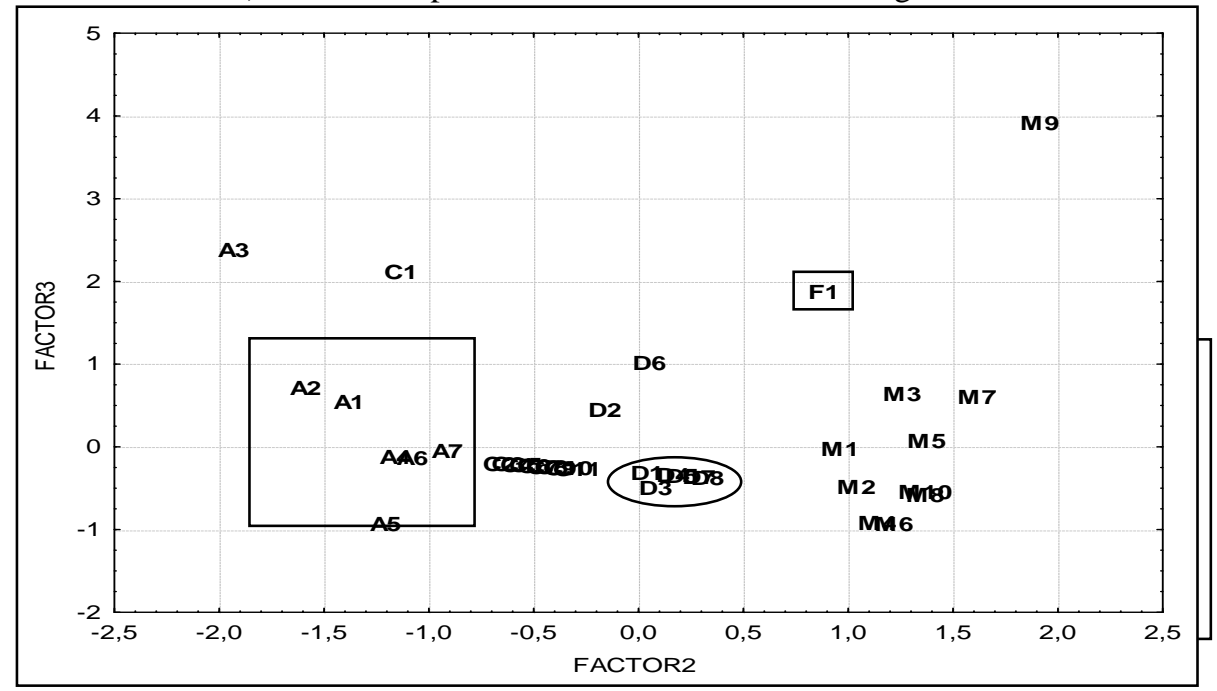

Figure 7. Bidimensional diagram (Factor 2 x Factor 3) indicating the interrelationships between the 37 genera of the Moraceae family analyzed in the present study. 
Surprisingly, the chemosystematic data of micromolecules resulting from mixed pathways separated the analyzed genera into two clusters, coinciding with singular floral and morphological characteristics, besides the breeding systems that regulate the Moraceae genera ecological and evolutionary aspects that characterize this taxon.

The formation of two major clusters, each consisting of three subgroups, can be observed in the dendrogram displayed in Figure 8. The first cluster consists of the association between genera belonging to the Moreae and Ficeae tribes, and also to some belonging to the Dorstenieae tribe. The second cluster is the result of the association of the Castilleae and Artocarpeae tribes.

The chemosystematic affinity between the Castilleae and Artocarpeae tribes is related to their chemical peculiarities, which are most probably due to their botanical and morphological characteristics, particularly, monoicism and bisexual inflorescences (Dätwbler \& Weiblen, 2004). Moreover, although the Castilleae tribe is entomophyllic and the Artocarpeae tribe is anemophyllic, due to the floral structures found in Artocarpeae, some genera are pollinated by insects, mainly the genus Artocarpus.

On the other hand, the species belonging to the Dorstenieae and Moreae tribes are closely interlinked due to being anemophyllic and, furthermore, presenting globous bisexual inflorescences, while the relationship between the Dorstenieae and Ficeae tribes is due to the fact they are both monoecious and present bisexual inflorescences, both possessing two stamens per flower. In summary, the cluster formed by the Castilleae and Artocarpeae tribes is characterized by mostly monoecious genera with unisexual inflorescences.

The Ficeae and Moreae tribes are also related, since their flavone/flavonol bioproduction ratios are close. For this reason, their representatives show intermediate stage indicators of flavone/flavonol bioproduction, namely glycosylated flavonoids, (Gottlieb, 1982; Smith \& Kaplan, 200), that only occur in these two tribes. The Ficeae and Dorstenia tribes, in turn, are both monoecious and display bisexual inflorescences. Conversely, the Moreae tribe, although composed by a vast majority of dioecious genera, aligns with the Dorstenieae tribe due to both being anemophyllic.

In sum, it is noteworthy that, although the affinity proposals from the chemosystematics data coincided with the phylogenetic analysis (Weiblen Dätwyler \& 2004), it is still necessary to consider the ecological aspects and evolutionary conditions that are the main encouragers of micromolecule production.

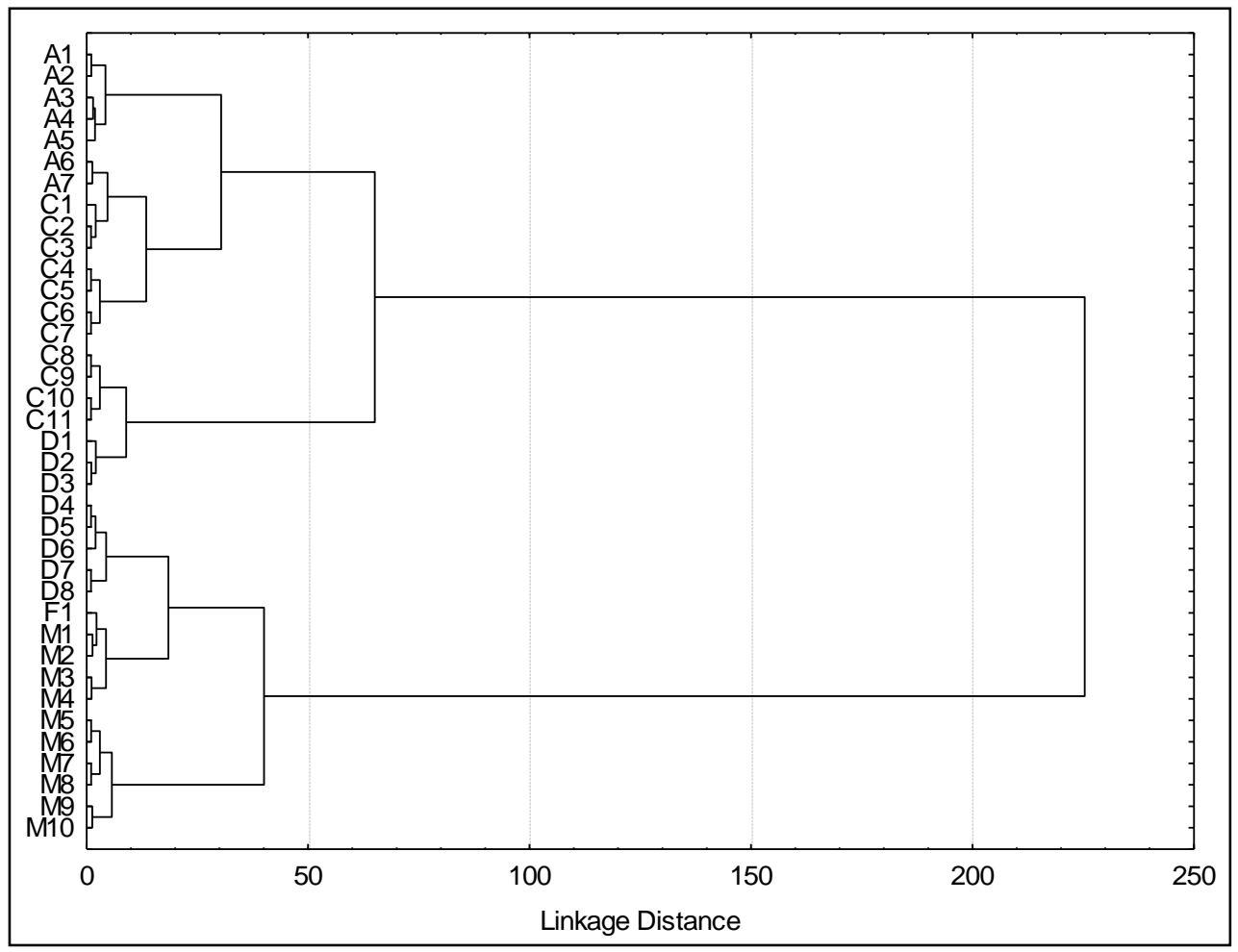

Figure 8. Dendrogram of 37 genera of the Moraceae family analyzed in the present study (Ward's method based on Euclidean Distance). 
After a preliminary analysis, the genera with no metabolite records in the literature were removed. Thus, the factor analysis led to Factor 1 being composed of the classification of the tribes and genera belonging to the Moraceae family (accounting for $36.61 \%$ of the total data variance), based on the study by Dätwyler and Weiblen (2004). Factor 2 (accounting for $22.92 \%$ of the total data variance) was composed of $\mathrm{O}$-methylation and $\mathrm{O}$-prenylation, while Factor 3 (accounting for $16.99 \%$ of the total data variance) was composed of total O-protection and total unprotection and Factor 4 (accounting for $10.76 \%$ of the total data variance) was composed of C-prenylation, $\mathrm{EA}_{\mathrm{O}}$ e $\mathrm{EA}_{\mathrm{E}}$.

The bidimensional diagram displayed in Figure 9, confronting Factors 1 and 2 also presented a high genera separation distance, and, as observed previously, O-methylation and O-prenylation values were decisive to this distribution. The affinities established between the investigated Moreae genera are closely related to the priorities for the use of protective mechanisms by $\mathrm{O}$-methylation versus $\mathrm{O}$ prenylation that every genus uses, as verified in the details of the previously discussed graph displayed in Figure 4. Thus, the distance between Streblus and the other Moreae genera is reaffirmed, since Streblus is the genus that presents the most hydroxyl protection by methylation in the Moreae tribe. Regarding the proximity of the Sorocea and Milicia genera, this is due to the fact that these taxa present protection by prenylation almost exclusively. Broussonetia, Maclura, Morus and Bagassa are distanced farther from each other due to the predominance of hydroxyl protection.

As seen in the dendrogram displayed in Figure 9, the monogeneric tribe Ficeae is distant from the Moreae tribe, since it prioritizes protection by methylation, while Moreae shows a predominance of protection by prenylation. The dendrogram also demonstrates dispersion between the Artocarpeae genera, which may be associated with the fact that each genus shows a specific protection trend. The distancing of the Paratocarpus genus from the tribe to which it is allocated, Artocarpeae, is clearly observable. Because of this, the discussion proposed by Zerega et al. (2010) is rekindled, that states that the Paratocarpus genus is in a conflicting phylogenetic positioning.

The distances between the Trilepsium, Dorstenia and Brosimum genera from the Dorstenieae tribe are clearly observable. The position of the Trilepsium genus on the graph can be associated with a greater unprotected trend, and, when protection mechanisms are in place, they occur primarily by methylation. Dorstenia prioritizes protecting its hydroxyl by prenylation and, finally, the Brosimum genus presents a similar ratio between protection by methylation and prenylation. 


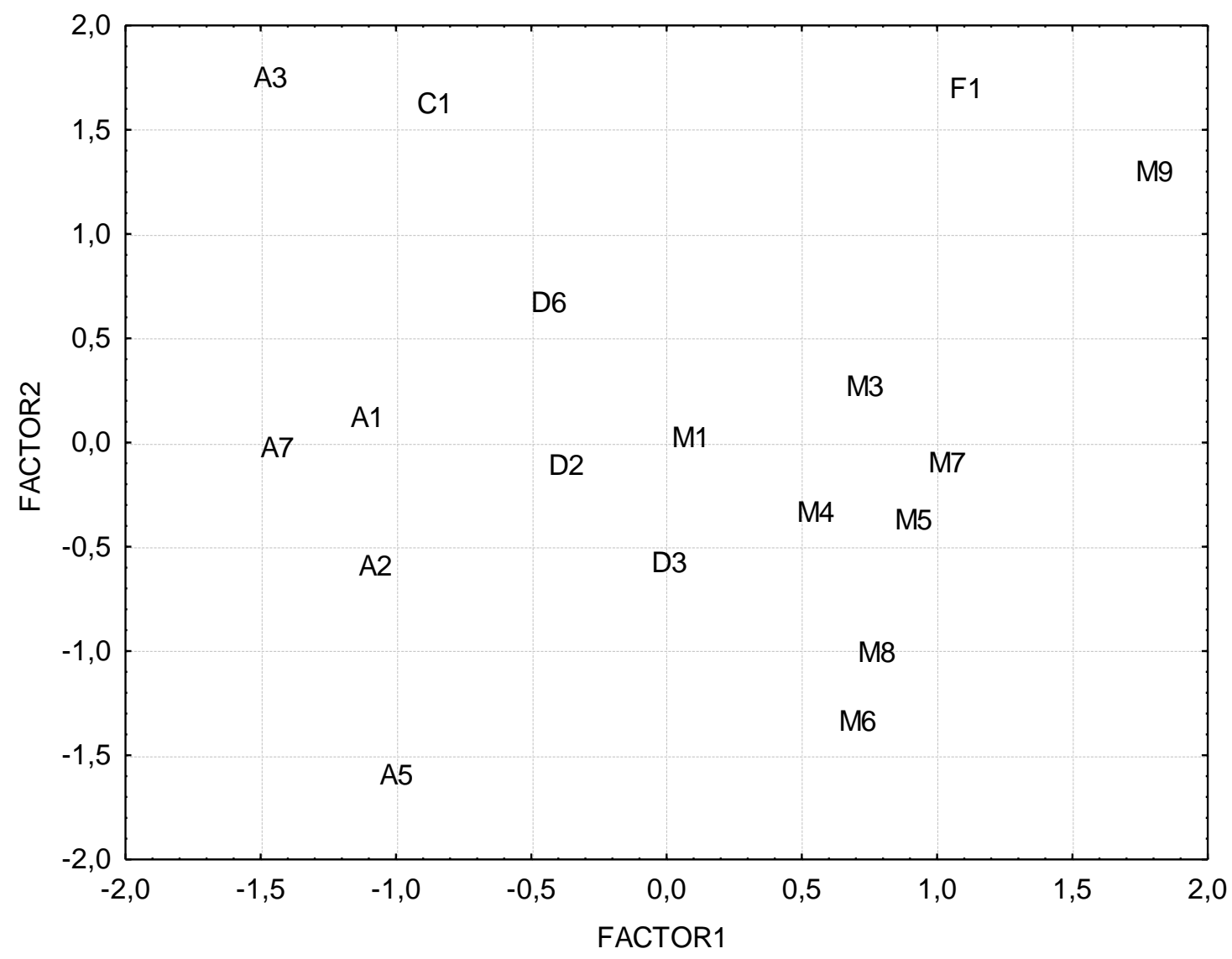

Figure 9. Bidimensional diagram (Factor 1 x Factor 2) the interrelationships between the 18 genera of the Moraceae family analyzed in the present study.

The Fatoua and Bagassa genera are the farthest from the Moreae tribe in terms of presenting the lowest hydroxyl protection index (Total O-Protection Fatoua: 0.0833; Total O-Unprotection Fatoua: 0.9167; Total OProtection Bagassa: 0.0667; Total O-Unprotection Bagassa: 0.8333). The Sorocea and Milicia genera, on the other hand, show similar Total O-protection and unprotection ratios, thus overlapping (Total OProtection $_{\text {Sorocea }}$ : 0.2262; Total O-Unprotection sorocea: 0.7883; Total O-Protection Milicia: 0.2167; Total OUnprotection Milicia: 0.7833), as occurs with the Maclura, Broussenetia and Morus genera, as well as the Ficus genus, that belongs to the Ficeae tribe. The Antiaris genus, that belongs to the Castilleae tribe, is associated with the Artocarpus and Clarissa genera. Both genera have in common a proximity between unprotected indices, as shown in Table 3.

The bidimensional graph displayed in Figure 10 (Factor 1 x Factor 3) shows the similarities and dissimilarities of the analyzed genera mainly in function of micromolecule hydroxyl protection versus unprotection. The distant position of Streblus in relation to the Moreae tribe is ratified, since this genus, as mentioned previously, has the highest hydroxyl protection and unprotection indices and, consequently, lower protection and unprotection rates.

At this point, the chemometric analysis corroborates the discussion presented previously (Zerega et al, 2010) in which the genus Treculia has more affinity with the Dorstenieae tribe than the Artocarpeae tribe. Moreover, a large dispersion between the belonging to the Artocarpeae tribe is generally observed, since each genus posesses a specific behavior for protection and unprotection. Thus, in addition to the Treculia, Artocarpus, Clarissa genera, the Batocarpus and Paratocarpus genera are also distanced far from each other. With regard to the Dorstenieae tribe, the Trilepsium genus, due to presenting a higher unprotection index (Total Ounprotection Trilepsium: 0.8750) is distanced from the Dorstenia (Total O-unprotection Dorstenia: 0.7866) and Brosimum (Total O-unprotection Brosimum: 0.7745) genera, which, in turn, have lower unprotection rates, meaning that they are more protected than the Trilepsium genus. 


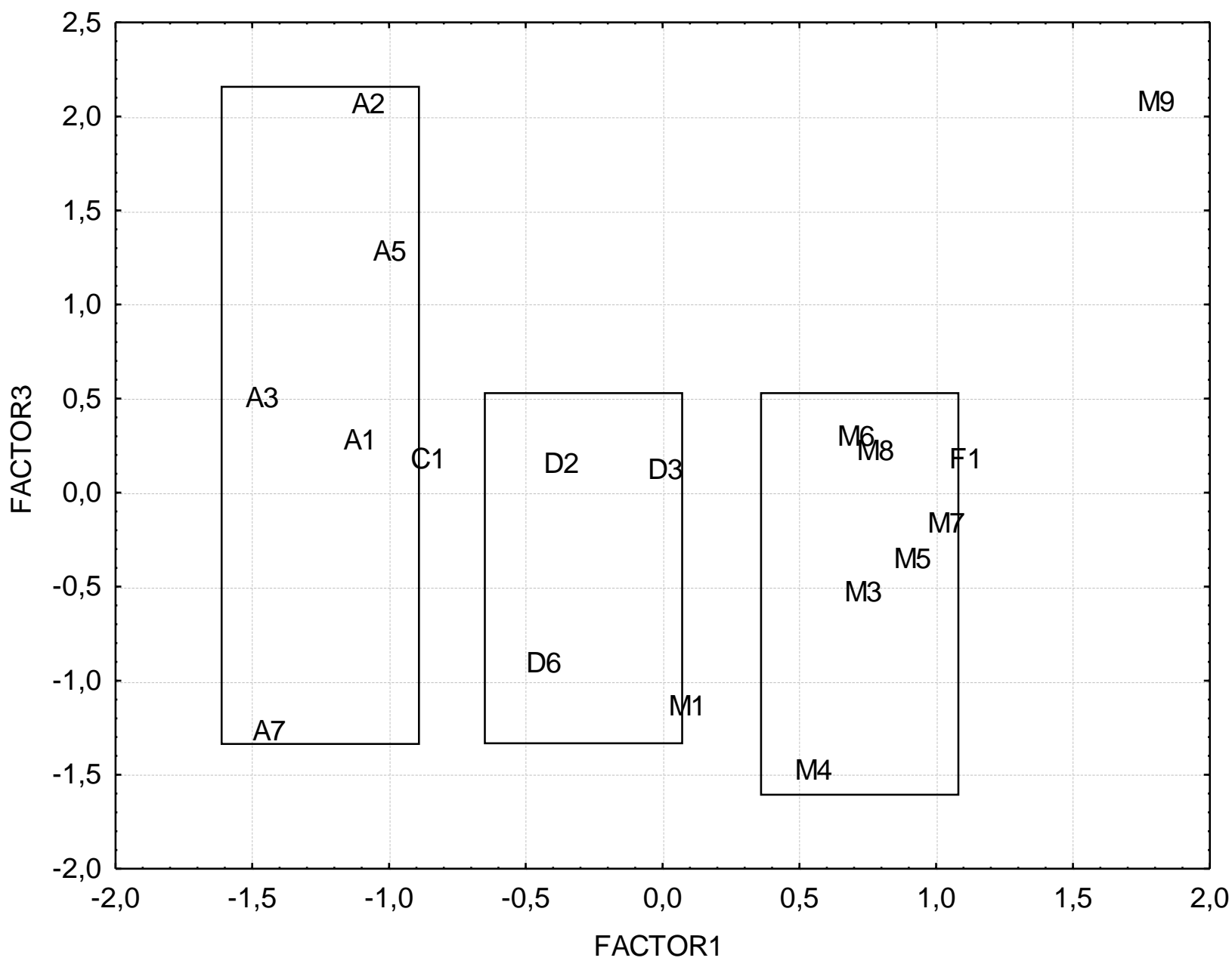

Figure 10. Bidimensional diagram (Factor 1 x Factor 3) the interrelationships between the 18 genera of the Moraceae family analyzed in the present study.

Considering the bidimensional diagram displayed in Figure 11, Factor 1 x Factor 4, the separation between genera can be observed as being governed by the specialization of micromolecules through the rates of $\mathrm{EA}_{\mathrm{E}}$ and $\mathrm{C}$-prenylation, and the oxidation evolutionary advance $\left(\mathrm{EA}_{\mathrm{O}}\right)$. By analyzing this in these terms, it is possible to observe the ratification for differences among genera belonging to the Dorstenieae tribe with regard to specialization and oxidative characters. Both the Dosrtenia and Brosimum genera have higher specialization indices (EA $\mathrm{E}_{\mathrm{E}}$ and C-Prenylation) than Trilepsium. This is not surprising, given the fact that both Dosrtenia and Brosimum are rich in protection by prenylation. Conversely, Trilepsium has a higher oxidation index

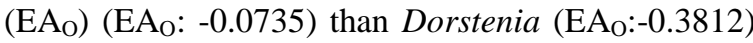
and Brosimum (EAo: -0.4675).
The Moreae tribe presents a grouping formed by the Milicia, Broussonetia, Morus, Maclura and Sorocea genera, between 0.5 and 1.0, in Factor 1. These Moreae representatives show similarities in their EAo, EA $A_{E}$ and $C$-prenylation rates. The other genera allocated in Moreae are dispersed. The Bagassa genus is located far from the Moreae tribe, due to a lower specialization index $(\mathrm{EA})$, and, as a result, presents the lowest C-prenylation index of this tribe, whereas the Fatoua genus is distanced from the Moreae tribe because it possesses prominent specialized features, such as high levels of specialization and C-prenylation. The Streblus genus also remains distanced from the tribe and has a high oxidation rate. The Ficeae tribe, monogeneric, is isolated from the Moraceae genera, as it is rich in CPrenylation (0.6589) and has a high oxidation $\left(\mathrm{EA}_{\mathrm{O}}\right.$ Ficeae: -0.0774) rate compared to the other investigated tribes. 


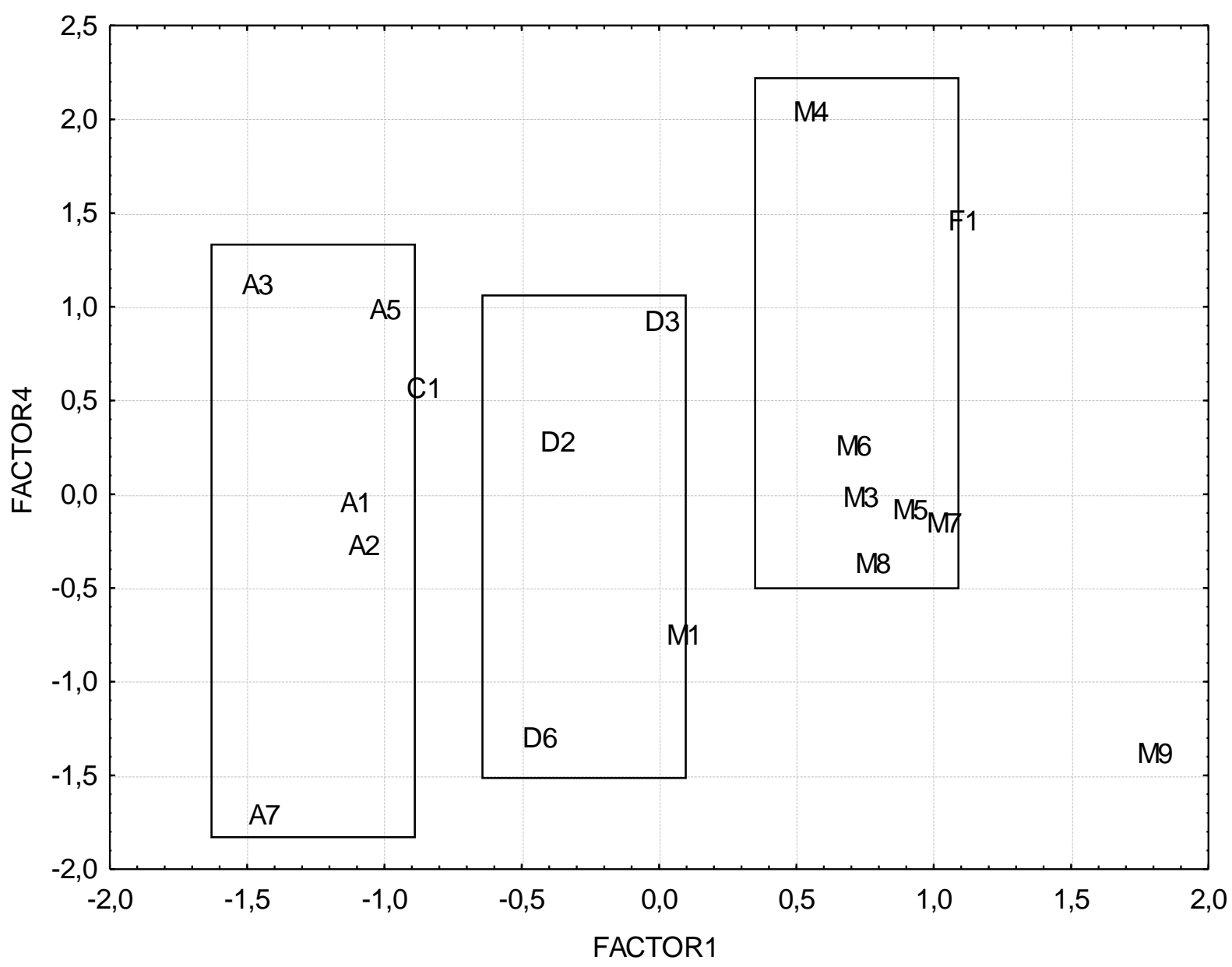

Figure 11. Bidimensional diagram (Factor 1 x Factor 4) the interrelationships between the 18 genera of the Moraceae family analyzed in the present study.

The dendrogram displayed in Figure 12 shows the formation of two major clusters. The first group consists of the association between the genera from the Artocarpeae and Castilleae tribes, while the second group is composed of genera from the Moreae, Ficeae and Dorstenieae tribes. As discussed previously, the organization from chemical characteristics coincides with the morphological and anatomical peculiarities of the Moraceae.

Hence, although several disagreements regarding associations guided by individual phylogenetics exist (Dätwyler \& Weiblen 2004), the genera were organized by chemical affinities in the dendrogram displayed in Figure 12, relating to each other due to similarities acquired in molecular evolution subsidized by biotic and abiotic factors. The first cluster can, thus, be explained by a careful analysis of morphological, anatomical and developmental characteristics of the Artocarpeae and Castilleae tribes.
The subgroup formed by the Artocarpus, Batocarpus and Clarissa genera have the same biogeographical divergence source (Zerega et al, 2005). Also corroborating this is the fact that both Batocarpus and Clarissa have yellow glands on their inflorescences and the same level of specialization $\left(\mathrm{EA}_{\mathrm{E}}\right)$, while Artocarpus and Batocarpus have the same level of oxidation $\left(\mathrm{EA}_{\mathrm{O}}\right)$. Both genera sustain typical Artocarpeae features, such as one stamen per flower, interfloral peltate bracts and straight filaments. Treculia, Antiaris and Paratocarpus, which constitute the second subcluster, are monoecious and unisexual, and have in common chalcone production.

The group formed by the Dorstenieae, Ficeae and Moreae tribes is divided into three subgroups because of the following peculiarities: Moreae and Ficeae both protect micromolecules hydroxyls by glycosylation and have the same chromosome number baseline (Sytsma et al 2002). Dorstenieae and Moreae, on the other hand, precisely because they are anemophilic, are rich in morphological similarities, including interfloral peltate bracts, straight filaments 
and inflorescences with a globous architecture, among others (Clement \& Weiblen, 2009; Sytsma et al 2002). Finally, Dorstenieae and Ficeae are monoecious and bisexual and possess straight filaments (Clement \& Weiblen, 2009).

Occasionally, the Ficus and Bagassa genera resemble each other because they have lower protection indices for prenylation in the Moraceae tribe, while the Broussonetia and Fatoua genera belong to the Moreae tribe and have phylogenetic affinities with the Artocarpeae tribe. In contrast, the Maclura and Milicia genera are dioecious, and have similar total $\mathrm{O}$-protection and C-Prenylation indices.

The subgroup formed by the Morus, Streblus and Sorocea genera belong to the Moreae tribe, and are phylogenetically ahead of the Artocarpeae tribe. Morus and Sorocea are associated by having similar oxidation $\left(\mathrm{EA}_{\mathrm{O}}\right), \mathrm{C}$-Prenylation and total Oprotection indices, and, furthermore, bioproduced Diels Alder adducts. Both genera are associated with Streblus because they have the same level of specialization $\left(\mathrm{EA}_{\mathrm{E}}\right)$.

The cluster composed of the Brosimum and Dorstenia genera can be attributed to the proximity of their Total O-protection indices. The Trilepsium genus, on the other hand, is far from both due to a prioritization of protection by methylation, while the former prefer prenylation. It should be noted that the Dorstenia tribe is phylogenetically closer to the Moreae tribe, which justifies the proximity among the genera that compose these tribes.

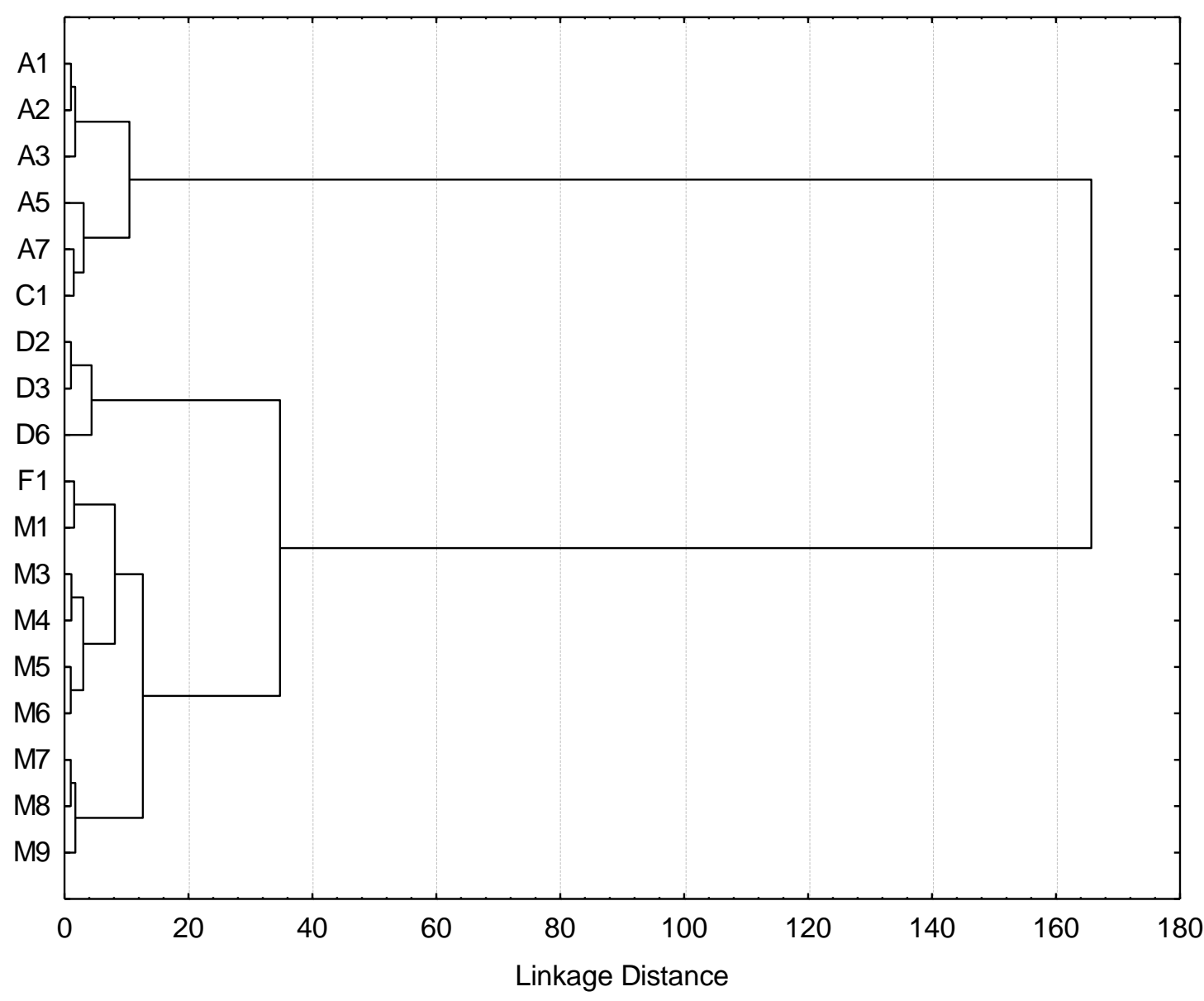

12. Dendrogram of the Moraceae family genera (Ward-Euclidean Distance method).

Figure

\section{Conclusions}

The Moraceae family metabolism appears to be conspicuous in the production of metabolites from a mixed pathway (acetate/shikimate) in comparison to other metabolic pathways. The high heterogeneity carried out by flavonoid derivatives corroborates Dalghren (1980) in its rating for angiosperms. There is a higher frequency of unprotected, rather than protected, flavonoid derivatives. However, the main hydroxyl protection mechanism is prenylation. Nevertheless, this taxon has some primitive characteristics in its metabolic production, such the high index of unprotected flavonoid hydroxyls. 
On the other hand, in the interest of the phenetics approach, in general, it cannot be said that the $\mathrm{EA}_{\mathrm{O}}$ and $\mathrm{EA}_{\mathrm{E}}$ calculations separated the Moraceae family into different groups, since they show similar characteristics for both oxidation and specialization. However, one fact is clear; the structures resulting from the Moraceae family, for this mixed route, are characterized by high levels of specialization.

Although not all records regarding the Moraceae family genera were used in the present study, the data obtained were sufficient to organize the genera in dendrograms to demonstrate the relationship between the genera and tribes. The dendrogram obtained is related to the phylogenetic systems and, mainly, to the floral, morphological and anatomical characteristics of the investigated genera, in addition to their pollination syndromes.

The main evidence obtained in the present study was the distance among Trilepsium and others Dorstenieae tribe genera, and among Streblus and others Moreae tribe genera, corroborating with the phylogenetic study of Dätwyler and Weiblen (2004), which had already pointed uncertainties in the positioning of these taxa.

Another interesting observation is that the Antiaris genus, that belongs to the Castilleae tribe, shows affinity to the genera from the Artocarpeae tribe. Furthermore, the chemosystematic discussion confirms the possibility of the Paratocarpus genus having a tribal status, since the chemical point of view is the genus in which micromolecule hydroxyls are highly protected by prenylation, which meets with the unique floral characteristics of this taxon, such as the pistillate and seeded inflorescences and absence of fruits.

Future steps include the study of the metabolites of the acetate and shikimate pathways and the evolutionary advanced parameters of the hydroxyl groups of phenolic substances (mixed pathway and the shikimate pathway). This has as aim the verification of chemical evolutionary relationships and will further contribute in the predictions of taxonomic relationships and in enlightening several remaining questions.

Chemosystematic studies through chemometric analyses can greatly contribute to intrafamily classification such as that regarding the Moraceae family still under discussion among Moraceae experts, since it is a dynamic system that applies both chemical and genetic characteristics to this classification problem.

\section{References}

1-APG III (Angiosperm Phylogeny Group). 2009. An update of the Angiosperm Phylogeny Group classification for the orders and families of flowering plants. Botanical Journal of Linnean Society. $161 \quad$ (2): $\quad 105-121 . \quad$ http://dx.doi.org/10.1111/j.10958339.2009.00996.x

2-Berg, Cornelis C. 1972. Olmediea e Brosimeae (Moraceae). Flora Neotropica. P. http://www.jstor.org/stable/4393672

3-Berg, Cornelis C. Moreae, Artocarpeae, and Dorstenia (Moraceae): with introductions to the family and Ficus and with additions and corrections to Flora NeotropicaMonograph7. Organization for Flora Neotropica, 2001.

4-Berg, C. C. "Flora Malesiana precursor for the treatment of Moraceae 8: other genera than Ficus." Blumea-Biodiversity, Evolution and Biogeography of Plants 50.3 (2005): 535-550. http://dx.doi.org/10.3767/000651903X489537

5-Carauta, J. P. P. 1980.Moraceae: Notas Taxonômicas. Rodriguésia. $\quad 32 \quad$ (53):

116.http://www.jstor.org/stable/23493662

6-Carauta, J.P.P.; Sastre, C.; Romaniuc-Neto, S. 1996. Índice das Espécies Moráceas do Brasil. Albertoa. 4 (7): 77-93. $\underline{\text { http://kbd.kew.org/kbd/detailedresult.do?id=313842 }}$

7- CLEMENT, W. W.; WEIBLEN, G.D.2009.MorphologicalEvolution in the Mulberry Family (Moraceae). Systematic Botany. 34(3): 530-552. http://dx.doi.org/10.1600/036364409789271155

8- Conn, Barry J. 2015. Re-straightening the story of Streblus brunonianus and S. pendulinus (Moraceae). Journal of Plant Systematics 18: 73-78.

http://dx.doi.org/10.7751/telopea8500

9- Dahlgren, R.M.T. 1980. A revised system of classification of the Angiosperms. Botanical Journal of the Linnean Society. Volume 80 ( 2): 91-124. http://dx.doi.org/10.1111/j.10958339.1980.tb01661.x

10-Datwyler, S. L.; Weiblen, G. D. 2004. On the origin the fig: Phylogenetic relationships of Moraceae from ${ }_{\mathrm{NDH}} \mathrm{F}$ sequences. 91 (5): 767-777. http://dx.doi.org/10.3732/ajb.91.5.767

11- GOTTLIEB, O. R. 1982. Micromolecular evolution, systematic and ecology: $\mathrm{Na}$ essay into a novel botanic discipline. Springer-verlag, Berlin Heidelber, New York.

12-GOTTLIEB, O. R.; KAPLAN, M. A. C.; BORIN, M. R. DE M. B. 1996. Biodiversidade: um enfoque químico-biológico. Editora UFRJ, Rio de Janeiro.

13- Harborne, Jeffrey B.1977. Flavonoids and the evolution of the angiosperms .Biochemical Systematics and Ecology. 5 (1): 7 22.http://dx.doi.org/10.1016/0305-1978(77)90013-8

14- Hair, Joseph F. 1999. Análisis multivariante. Vol. 491. Madrid: Prentice Hall.

15- Ribeiro, J.E.L.S. 2007.Estudos sobre a filogenia, taxonomia e evolução de caracteres reprodutivos em Moraceae Gaudich. Tese de Doutorado, Universidade Estadual de Campinas, Campinas-SP. 16-Romaniuc Neto, S.; Carauta, J.P.P.; Vianna Filho, M.D.M.; Pereira, R.A.S.; Ribeiro, J.E.L. da S.; Machado, A.F.P.; Santos, A. dos; Pelissari, G.; Pederneiras, L.C. (2010). Moraceae in Lista de Espécies da Flora do Brasil. Jardim Botânico do Rio de Janeiro. Rio de Janeiro, RJ. See: http://floradobrasil.jbrj.gov.br/jabot/floradobrasil/FB167

17-Romaniuc Neto, S. 1999. "Cecropioideae (CC Berg) RomaniucNeto stat. nov.(Moraceae-Urticales)." Albertoa. 4: 13-16.

18-Romaniuc- Neto, S. Gaglioti, A.L. \& Guido, B.D.O. 2009. Urticales Jussofthe Parque Estadual das Fontes do Ipiranga, São Paulo, SP, Brasil. Hoehnea 36(1), 193-205. http://dx.doi.org/10.1590/S2236-89062009000100012

19-Soares, Geraldo. G.; Kaplan, Maria . C. 2001 Analysisofflavone-flavonol ratio in Dicotyledoneae. Botanical Journal of the Linnean Society. 135 (1): 61-66. http://dx.doi.org/10.1006/boj1.2000.0357

20- Soltis, Douglas E.; Moore, Michael J.; Burleigh, J. Gordon; Bell, Charles D.; Soltis, Pamela S.2010. Assembling the Angiosperm tree of life: progress and future prospects. Missouri 
A Chemosystematic Study of the Moraceae Family: An Analysis of the Metabolites from the Biosynthetic Mixed Pathway (Acetate/Shikimate)

Botanical Garden Press. Vol. 97, No. 4 pp. 514-526. http://dx.doi.org/10.3417/2009136

21 -Sytsma, Kenneth J.; Morawetz, Jeffery; Pires, J. Chris; Nepokroeff, Molly; Conti, Elena; Zjhra, Michelle; Hall, Jocelyn C.; Chase, Mark W. 2002. Urticalean Rosids: Circumscription, Rosid Ancestry, And Phylogenetics Based On RBCL, TRNL-F, And NDHF Sequences. American Journal of Botany 89(9): 15311546. http://dx.doi.org/10.3732/ajb.89.9.1531
22- Zerega, N. J.C.; Clement, W. L.; Datwyler, S. L.; Weiblen, G. D. 2005. Biogeography and divergence times in the mulberry family (Moraceae).Molecular Phylogenetics and Evolution. 37 (2): 402-416. http://dx.doi.org/10.1016/j.ympev.2005.07.004

23- Zerega, N. J.; Supardi,M.N. \& Motley, T.J. (2010)

Phylogenyand recircumscription of Artocarpeae (Moraceae) with a focus on Artocarpus. Systematic Botany, 35(4), 766-782. http://dx.doi.org/10.1600/036364410X539853 